Pharmaceutical Co.,Ltd., Tadashi Okano Speakers bureau: AbbVie, Yutaro Yamada Speakers bureau: Abbvie, Chugai, Mitsubishi Tanabe, Masahiro Tada Speakers bureau: Abbvie, Astellas Pharma, Bristol-Myers Squibb, Chugai Pharmaceutical, Eisai, Janssen Pharmaceutical, Mitsubishi Tanabe Pharma Corporation, Ono Pharmaceutical, Pfizer Japan, Takeda Pharmaceutical, Kenji Mamoto: None declared, Shohei Anno: None declared, Hiroaki Nakamura: None declared

DOI: 10.1136/annrheumdis-2019-eular.1317

\section{AB0269 COMPARISON BETWEEN DIFFERENT DISEASE ACTIVITY SCORES IN ELDERLY ONSET RHEUMATOID ARTHRITIS}

Melania Martínez-Morillo, Águeda Prior-Español, Anahy Brandy-Garcia, Susana Holgado, María Aparicio-Espinar, Laia Gifre, Anne Riveros-Frutos, Clara Sangüesa-Gomez, Jordi Camins-Fàbregas, Ivette Casafont-Solé, Annika Nack, Alejandro Olive, Lourdes Mateo Soria. Hospital Germans Trias i Pujol, Rheumatology, Badalona, Spain

Background: Elderly onset rheumatoid arthritis (EORA) has several peculiarities. Which activity index should we use in this age group is still an unresolved issue. The use of ESR in DAS28 is widespread, but it is well known that ESR could increase with age, overestimating activity. DAS28-PCR or SDAI, which uses PCR, or CDAl that does not use analytical data, could be more suitable alternatives.

Objectives: To describe disease activity scores evolution in EORA and to analyse the correlation and concordance between them.

Methods: Longitudinal observational study in naïve treatment EORA patients (ACR/EULAR 2010 criteria). Study visits were carried out basally (pre-treatment) and at month 1, 3, 6 and 12. DAS28 VSG, DAS28 PCR, SDAI and CDAl were calculated at each visit, and ACR/EULAR remission index at 12 months. The same rheumatologist made all visits and explorations. Correlations were analysed using the Spearman or Pearson correlation index ( $p$ value $\leq 0.001$ ). The concordance was evaluated with the kappa index. The statistical study was performed with Stata 15.1 .

Results: 45 patients with EORA were enrolled. Table 1 and 2 summarize the clinical and analytical characteristics.

All the scores had a very good linear correlation both at baseline and at follow-up (correlation score: 0.83-0.98). A moderate concordance was observed from the baseline visit between DAS28-VSG and DAS28-PCR $(k=0.43-0.52, p<0.001)$, which decrease to low at 12 months $(k=0.32, p$ $<0.001$ ). A concordance of $100 \%$ was observed at baseline analysing DAS28-VSG and SDAI ( $k=1 ; p<0.001)$, but worsened during follow-up being moderate $(\mathrm{k}=0.40-056 ; \mathrm{p}<0.001)$. A very good concordance was observed comparing DAS28-VSG to CDAl at the baseline visit $(k=0.88$, $\mathrm{p}<0.001)$, which decreased to good-moderate during follow-up ( $k=0.40$ $0.63, p<0.001)$. Between DAS28-PCR and SDAI a moderate concordance

\begin{tabular}{|c|c|c|c|c|c|c|}
\hline & & & & & & $\mathrm{N}=45$ \\
\hline \multicolumn{7}{|l|}{ Epidemiological data } \\
\hline \multicolumn{6}{|l|}{ Women n (\%) } & $21(46.7)$ \\
\hline \multicolumn{6}{|l|}{ Age (mean $\pm \sigma)$} & $74.8 \pm 7.5$ \\
\hline \multicolumn{7}{|l|}{ Symptoms n (\%) } \\
\hline \multicolumn{6}{|l|}{ Shoulder girdle } & $34(75.6)$ \\
\hline \multicolumn{6}{|l|}{ Pelvic girdle } & $20(44.4)$ \\
\hline \multicolumn{6}{|l|}{ Peripheral joints } & $45(100)$ \\
\hline \multicolumn{6}{|l|}{ Oedema } & $21(46.7)$ \\
\hline \multirow{2}{*}{\multicolumn{7}{|c|}{$\begin{array}{l}\text { Small joints of hands } \\
\text { Analytical and radiological data } n(\%)\end{array}$}} \\
\hline & & & & & & \\
\hline \multicolumn{6}{|l|}{$\mathrm{FR}+$} & 15 (33.3) \\
\hline \multicolumn{6}{|l|}{$\mathrm{ACPA}+$} & $13(28.9)$ \\
\hline \multicolumn{6}{|l|}{ FR and ACPA + } & $10(22.2)$ \\
\hline \multicolumn{6}{|l|}{ Bone erosions } & $4(8.8)$ \\
\hline \multicolumn{7}{|l|}{ Treatments $\mathrm{n}(\%)$} \\
\hline \multicolumn{6}{|l|}{ Glucocorticoids } & $43(95.5)$ \\
\hline \multirow[t]{2}{*}{ DMARDs } & & & & & & $40(91.1)$ \\
\hline & $\begin{array}{c}\text { Baseline } \\
\mathrm{N}=45\end{array}$ & $\begin{array}{c}\text { Month } 1 \\
\mathrm{~N}=45\end{array}$ & $\begin{array}{c}\text { Month } 3 \\
\mathrm{~N}=44\end{array}$ & $\begin{array}{c}\text { Month } \\
6 \\
N=44\end{array}$ & $\begin{array}{c}\text { Month } \\
12 \\
\mathrm{~N}=44 \\
\end{array}$ & $\begin{array}{c}\% \text { remission } \\
\text { Month } 12 \\
\mathrm{~N}=44\end{array}$ \\
\hline $\begin{array}{l}\text { DAS28-VSG (mean } \\
\pm \sigma)\end{array}$ & $6.3 \pm 1.0$ & $\begin{array}{c}2.9 \pm \\
1.7\end{array}$ & $\begin{array}{c}3.0 \pm \\
1.4\end{array}$ & $\begin{array}{c}2.8 \pm \\
1.3\end{array}$ & $\begin{array}{c}3.1 \pm \\
1.3\end{array}$ & 40.9 \\
\hline $\begin{array}{l}\text { DAS28-PCR (mean } \\
\pm \sigma \text { ) }\end{array}$ & $5.7 \pm 1.0$ & $\begin{array}{c}2.5 \pm \\
1.4\end{array}$ & $\begin{array}{c}2.4 \pm \\
1.3\end{array}$ & $\begin{array}{c}2.2 \pm \\
1.1\end{array}$ & $\begin{array}{c}2.5 \pm \\
1.0\end{array}$ & 70.4 \\
\hline SDAI $($ mean $\pm \sigma)$ & $\begin{array}{c}41.0 \pm \\
13.8\end{array}$ & $\begin{array}{c}9.3 \pm \\
11.1\end{array}$ & $\begin{array}{l}7.9 \pm \\
10.7\end{array}$ & $\begin{array}{c}6.9 \pm \\
8.7\end{array}$ & $\begin{array}{c}7.5 \pm \\
8.0\end{array}$ & 31.8 \\
\hline $\operatorname{CDAl}($ mean $\pm \sigma)$ & $\begin{array}{c}36.9 \pm \\
11.6\end{array}$ & $\begin{array}{c}8.7 \pm \\
10.4\end{array}$ & $\begin{array}{c}7.4 \pm \\
10.5\end{array}$ & $\begin{array}{c}6.4 \pm \\
8.5\end{array}$ & $\begin{array}{c}6.8 \pm \\
7.9\end{array}$ & 31.8 \\
\hline $\begin{array}{l}\text { ACR/EULAR } \\
\text { remission }\end{array}$ & & & & & & 18.2 \\
\hline
\end{tabular}

was observed up to 6 months $(k=0.43-0.57, p<0.001)$, which worsened to low at 12 months $(\mathrm{k}=0.32, \mathrm{p}<0.001)$. The concordance between DAS28-PCR and CDAl was low-moderate ( $k=0.26-0.48, p<0.001)$. On the other side, the agreement was very good between SDAI and CDA throughout the follow-up ( $k=0.86-0.93, p<0.001)$. The ACR/EULAR index had a very low concordance with DAS28-PCR ( $k=0.17, p<0.001)$, moder ate with DAS28-VSG $(\mathrm{k}=0.49, \mathrm{p}<0.001)$ and the results are good with SDAI and CDAI ( $k=0.64, p<0.001)$.

Conclusion: The correlation between the different scores was good. How ever, the concordance between all the scores decreases as time passes, according to a higher percentage of patients in remission or low activity. This low-moderate concordance is demonstrated even between DAS28 PCR and DAS28-VSG, and when these are compared with CDAl and SDAI. CDAI and SDAI are the only ones that maintain a good concord ance between them, even when the number of patients in remission or low activity increases. ACR/EULAR only maintains an acceptable concord ance with the most restrictive scores, SDAI and CDAI. By contrast, agreement is very low with DAS28, especially by DAS-PCR.

Disclosure of Interests: None declared

DOI: 10.1136/annrheumdis-2019-eular.3453

\section{AB0270 1 POSITIVE ACPA WITHOUT EVIDENCE OF ARTHRITIS - A RARITY?}

Daniela Martins ${ }^{1}$, Graça Sequeira ${ }^{2} .{ }^{1}$ Centro Hospitalar Universitário do Algarve, Faro, Portugal; ${ }^{2}$ Centro Hospitalar Universitário do Algarve, Rheumatology, Faro, Portugal

Background: Rheumatoid Arthritis (RA) follows a variable disease course in regards to joint damage and functional outcome, therefore an early diagnosis is crucial for its management. However, occasionally, this diagnosis can be a challenge. Rheumatoid Factor (RF) and Anti-citrullinated peptide antibodies (ACPA) are the most useful biomarkers in the diagnosis of RA and, although individually they do not dictate the final diagnosis, they present high specificity and may be positive even before clinical manifestations of the disease occur.

ACPA is detected in approximately two thirds of the patients with RA and presents a superior diagnostic specificity when compared to RF. This specificity of $95-98 \%$ may present an increased value if it is three times superior to its value of reference.

Objectives: Share with the medical community and alerting them for the existence of patients with positive ACPA with no clinical evidence of RA. Methods: By consulting the electronic clinical records of patients observed by a Rheumatologist, we identified and analyzed the patients that presented positive ACPA in their blood tests and no evidence of signs or symptoms of RA, during at least six years of follow-up. Patients with other rheumatic diseases, history of tuberculosis or chronic pulmonary dis eases were excluded.

Results: We identified seven patients (average of 61 years old) with positive ACPA in at least two different blood tests, of which five presented a value three times superior to its normal value $(<15 \mathrm{UA} / \mathrm{mL})$. It should be noted that, four patients presented both positive ACPA and RF. Clinically, all patients referred mechanical symptoms that varied between cervical, low back, shoulder and knee pain and did not present any record of swollen joints without trauma. Radiologically, in most cases we observed joint degenerative damage. Six years after the first positive ACPA, none of the patients developed any manifestation of inflammatory joint disease. Conclusion: Studies reveal that positive ACPA in healthy patients may precede the clinical diagnosis of RA. The specificity of positive ACPA and RF one and a half years before the diagnosis of RA is approximately $99-100 \%$. However, as we demonstrated, it is not uncommon to find during clinical practice individuals with positive ACPA without evidence of arthritis, which leads us to emphasize the importance of a detailed anamnesis with a meticulous physical examination before establishing a diagnosis based on the patient's blood tests.

\section{REFERENCES}

[1] Moeez S, et al. Anti-citrullinated protein antibodies: role in pathogenesis of RA and potential as a diagnostic tool. Rheumatol Int. 2013;33(7):1669-73

[2] Brito Rocha, et al. Clinical and pathophysiologic relevance of autoantibodies in rheumatoid arthritis. Advances in Rheumatology. 2019;59:2

[3] Nielsen SF, et al. Elevated rheumatoid factor and long term risk of rheu matoid arthritis: a prospective cohort study. BMJ. 2012;345:e5244

[4] Rantapää-Dahlqvist S. What happens before the onset of rheumatoid arthritis? Curr Opin Rheumatol. 2009;21:272

[5] Bugatti S, et al. The Clinical Value of Autoantibodies in Rheumatoid Arthritis. Front. Med. 2018;5:339 